\title{
Analysis of Nonformulary Use of PPIs and Excess Drug Cost in a Veterans Affairs Population
}

\author{
Adewale B. Ajumobi, MD, MBA, FACP; Ronald Vuong, BS; and Hycienth Ahaneku, MBBS, MPH
}

\begin{abstract}
BACKGROUND: In the Veterans Affairs (VA) health care system, a formularybased approach without beneficiary cost-share incentives is used to limit the pharmacy cost of proton pump inhibitors (PPIs). However, the effectiveness of this approach in reducing the cost of PPIs is unknown.
\end{abstract}

OBJECTIVES: To (a) compare cost differences between the formulary PPI (generic omeprazole) and nonformulary PPIs and (b) evaluate reasons for nonformulary PPI use in order to identify opportunities to increase formulary drug use and discourage unnecessary use of nonformulary PPIs.

METHODS: A list of patients with receipt of PPIs from July 1, 2008, through June 30, 2009, was obtained from the Loma Linda VA Healthcare System pharmacy. Subjects with receipt of at least 120 units (capsules or tablets) of any PPI in the study period were considered long-term users. Demographic information was collected. Pharmacy consult records were reviewed to identify reasons for nonformulary use and dosing regimen of the formulary PPI prior to the switch. Cost analysis was done based on the VA contract prices for the drugs at the time of the study.

RESULTS: Of 58,605 unique patients seen in this VA health care system in the 12-month period from July 1, 2008, through June 30, 2009, 13,713 (23.4\%) received a PPI, and of these, 10,483 (76.4\%) received at least 120 PPI units and were defined as long-term users. Of the long-term users, 9,462 (90.3\%) were on the formulary PPI generic omeprazole, and 1,021 were nonformulary PPI users. Use of nonformulary PPIs (esomeprazole, pantoprazole, lansoprazole, rabeprazole) accounted for $10.5 \%$ of the PPI units and $9.7 \%$ of the users but $57.3 \%$ of total PPI cost. This pattern resulted in $\$ 570,263$ in excess spending (i.e., $\$ 570,263$ would have been saved in the study period if the nonformulary PPI users had used the formulary drug). The most common reason for nonformulary long-term PPI use was persistent symptoms $(n=901,88.2 \%)$. Adverse reaction was cited by $111(10.9 \%)$ of nonformulary PPI users, $33.3 \%(n=37)$ of whom reported diarrhea. Of those who switched to a nonformulary PPI due to persistent symptoms, 363 (40.3\%) were on once-daily dosing prior to the switch; 379 (42.1\%) were on twice-daily dosing; and 159 (17.6\%) were transfers from other places in which prior dosing information was not available in the hospital pharmacy records.

CONCLUSIONS: One-year PPI use prevalence was $23 \%$ in this VA population, and long-term use prevalence was $18 \%$. Nonformulary PPI use accounted for $10.5 \%$ of the PPI units and $9.7 \%$ of the users but $57.3 \%$ of total PPI drug cost. Opportunities to reduce nonformulary PPI use in order to reduce overall expenditures on PPIs include verification of optimal formulary PPI use, titration to twice-daily dosing, and confirmation of adverse reaction as being attributable to $\mathrm{PPI}$ use.

J Manag Care Pharm. 2012;18(1):63-67

Copyright $\odot 2012$, Academy of Managed Care Pharmacy. All rights reserved.

\section{What is already known about this subject}

- In studies conducted from 1991 to 2003, between 0.5\% and 5.0\% of the population used antisecretory medications on a long-term basis and were identified using a variety of definitions ranging from 1 repeated prescription over 12 months to continuous therapy for periods ranging from 4 to greater than 12 months.

\section{What this study adds}

- In a sample of veterans using PPIs long term (defined as receipt of 120 units or more during a 1-year period), the 10\% who used a PPI other than the formulary PPI, generic omeprazole, accounted for $57 \%$ of PPI cost.

- Reported reasons for nonformulary PPI use included persistent symptoms (88\%) and adverse reaction to the formulary PPI (11\%). Although the Veterans Affairs health care system requires a pharmacy consult to permit nonformulary PPI use, there is no clear guideline for what constitutes therapeutic failure or intolerance, and there are opportunities to reduce nonformulary PPI use that include verification of optimal use of the formulary drug and investigation of whether a reported adverse reaction is attributable to the PPI

$\mathrm{M}$ ore than 119 million prescriptions for proton pump inhibitors (PPIs) were filled in 2009, making this class of drugs, at $\$ 13.6$ billion in sales, the thirdhighest in sales in the United States. ${ }^{1}$ PPIs are primarily used for the management of gastroesophageal reflux disease (GERD) and its complications. Most users of PPI are long-term users, which varies from 1 repeated prescription over 12 months to continuous therapy for periods ranging from 4 months to more than 12 months. ${ }^{2}$ There is currently no consensus definition of long-term users, ${ }^{2}$ and intermittent PPI use is often included in the definition of "long-term" use. Various studies conducted between 1991 and 2003 have found that between 0.5\% and $5.0 \%$ of the population used antisecretory medications on a long-term basis. ${ }^{3-10}$

The Veterans Affairs (VA) health care system, unlike most private health systems, does not use beneficiary cost-share incentives for formulary management. In incentive-based formularies, the patient's copayment increases for the use of more expensive nonformulary medications. At the VA, however, the patient's copayment is the same regardless of the formulary 
status of the medication. The VA health system has formulary and nonformulary PPI use without a clear guideline on what constitutes a formulary PPI failure. To use a nonformulary PPI, a pharmacy consult is required in which the prescriber is required to state the PPI currently being used by the patient, the dose, the reason for the change to a nonformulary PPI, and the name and dose of the nonformulary PPI. The nonformulary drug is usually approved if the reason for change is persistent symptoms or presence of an adverse reaction (e.g., nausea, diarrhea, abdominal pain).

At a large VA health system, the formulary PPI is generic omeprazole. At the time of the study, the cost to the VA of omeprazole 20 milligrams (mg) was $\$ 0.13$ per capsule, while the costs per unit for nonformulary PPIs were $\$ 0.82$ for pantoprazole $20 \mathrm{mg}, \$ 2.72$ for rabeprazole $40 \mathrm{mg}, \$ 3.01$ for lansoprazole $15 \mathrm{mg}$, and $\$ 3.19$ for esomeprazole $20 \mathrm{mg}$. It is unknown whether use of a nonformulary PPI without beneficiary costshare incentives is effective at limiting PPI expenditure. The aim of this study was to compare cost differences between the formulary PPI and nonformulary PPIs and to identify reasons for use of a nonformulary PPI in order to identify opportunities to increase formulary drug use and discourage unnecessary nonformulary use of PPIs.

\section{Methods}

\section{Study Design and Patient Population}

The study was a cross-sectional assessment of patients seen at the Loma Linda VA Healthcare System. The Loma Linda VA Healthcare System consists of a medical center affiliated with a major university and 5 community clinics. The study sample included all unique patients with receipt of at least 120 units of PPI between July 1, 2008, and June 30, 2009. The definition of long-term use was similar to the one used by Reimer and Bytzer (2009) in which patients with receipt of prescriptions for at least 120 tablets of any PPI in the previous 12 months were considered long-term users. ${ }^{5}$ This definition includes ondemand (intermittent) users of PPI, who on average use 1 tablet or capsule of PPI every 3-4 days, equivalent to at least 120 tablets or capsule per year. ${ }^{11,12}$ Because 90 -day supplies may be dispensed in the VA clinic pharmacies or by mail order, longterm PPI users in the present study could include patients with as little as 1 dispensing.

\section{Data Collection and Analysis}

A clinical informatics pharmacist provided a list of all patients who received a PPI from July 1, 2008, through June 30, 2009, including the name of the PPI and the total number of PPI units dispensed to each patient. The list was revised to include only those patients who received at least 120 units of PPI in the study period. Demographic information including age, gender, and ethnicity was obtained from the electronic medical record.

Pharmacy consults (part of the patient's medical record) for nonformulary PPI were reviewed by the investigators to iden- tify the reason for switching to a nonformulary PPI. The dosage regimen of the PPI used prior to the switch was noted.

The cost comparison was based on PPI units dispensed in the study period and the unit price of the PPI (according to the VA contract price at the time of the study). This study was approved by the Institutional Review Board (IRB) of the Loma Linda VA Healthcare System.

\section{Results}

Of the 58,605 unique patients seen in this VA health care system in the 12-month period from July 1, 2008, through June $30,2009,13,713$ (23.4\%) received a PPI. Of these PPI users, 10,483 (76.4\%) received at least 120 PPI tablets and were defined as long-term users. Therefore, the prevalence of longterm PPI use was $17.9 \%$ in this patient population. The mean (standard deviation) age was 67 (13) years; 92\% were aged 50 years or older; and $94 \%$ were male. Ethnicity was documented as known in only 3,647 . Of these, whites were $76 \%$, and the rest were nonwhites.

Overall, 9,462 (90.3\%) of long-term PPI users were on generic omeprazole, indicating that most patients were prescribed the formulary PPI. Pantoprazole was used by 731 (7.0\%) and lansoprazole by 176 (1.7\%). Rabeprazole and esomeprazole were each used by 57 (0.54\%) of long-term PPI users. In total, 1,021 (9.7\%) of long-term PPI users were on a nonformulary PPI. A total of 3,577,635 capsules of generic omeprazole was dispensed in the study period. The number of nonformulary PPI units dispensed was 419,406. Formulary and nonformulary PPI costs accounted for $\$ 465,092.55$ and $\$ 624,785.46$ respectively (Table 1 ). Formulary (omeprazole) PPI use accounted for $89.5 \%$ of the PPI units and $90.3 \%$ of the users but only $42.7 \%$ of total PPI drug cost. The 1,021 nonformulary PPI users (10.7\%) accounted for $\$ 570,263$ in excess spending (i.e., $\$ 570,263$ would have been saved in the study period if the nonformulary PPI users had used the formulary drug; Table 1).

The reasons for switching from generic omeprazole to a nonformulary PPI were persistent symptoms ( $\mathrm{n}=901,88.1 \%$ ), adverse reactions $(n=111,10.9 \%)$, and presence of percutaneous endoscopic gastrostomy (PEG) tube $(n=9,0.9 \%)$. Of those who switched to a nonformulary PPI due to persistent symptoms, $363(40.3 \%)$ were on once-daily dosing prior to the switch; 379 (42.1\%) were on twice-daily dosing prior to the switch; and 159 (17.6\%) were transfers from other settings in which prior dosing information was not available in the hospital pharmacy records. The most common adverse reactions were diarrhea $(37,33.3 \%)$, nausea and vomiting $(20,18.0 \%)$, abdominal pain $(16,14.4 \%)$, headaches $(10,9.0 \%)$, rash $(5$, $4.5 \%)$, hives $(4,3.6 \%)$, and edema (3, 2.7\%). Dizziness, gynecomastia, lethargy, bloating, and flatulence had $2(1.8 \%)$ cases each. Myalgia, tachycardia, pruritus, cough, lightheadedness, and constipation each contributed $1(0.9 \%)$ adverse reaction case. 
Analysis of Nonformulary Use of PPIs and Excess Drug Cost in a Veterans Affairs Population

\section{TABLE 1 Cost Differences Between Formulary and Nonformulary} Long-Term PPI Users (July 1, 2008 - June 30, 2009)

\begin{tabular}{|c|c|c|c|c|c|c|c|c|c|}
\hline $\begin{array}{l}\text { Proton Pump } \\
\text { Inhibitor }\end{array}$ & \multicolumn{2}{|c|}{$\begin{array}{l}\text { Patients } \\
\text { n } \\
\text { (\% Total) }\end{array}$} & \multicolumn{2}{|c|}{$\begin{array}{c}\text { Mean } \\
\text { [Median] } \\
\text { Units Per Patient }\end{array}$} & $\begin{array}{c}\text { Units Per } \\
\text { Year }\end{array}$ & $\begin{array}{l}\text { Cost Per } \\
\text { Unit }(\$)^{\mathrm{a}}\end{array}$ & $\begin{array}{l}\text { Total PPI } \\
\text { Cost }(\$)\end{array}$ & $\begin{array}{c}\text { Excess PPI Cost } \\
\text { in } \$(\% \text { Total } \\
\text { Excess Cost })\end{array}$ & $\begin{array}{l}\text { Mean Cost } \\
\text { Per Patient } \\
\text { Per Year }(\$)\end{array}$ \\
\hline \multicolumn{10}{|l|}{ Formulary } \\
\hline Omeprazole $20 \mathrm{mg}$ & 9,462 & $(90.3)$ & 378 & [360] & $3,577,635$ & 0.13 & 465,093 & - & 49 \\
\hline \multicolumn{10}{|l|}{ Nonformulary } \\
\hline Pantoprazole $40 \mathrm{mg}$ & 731 & $(7.0)$ & 396 & [360] & 289,480 & 0.82 & 237,374 & $199,741 \quad(35.0)$ & 325 \\
\hline Lansoprazole $30 \mathrm{mg}$ & 163 & (1.6) & 474 & [390] & 77,186 & 3.01 & 232,330 & $222,296 \quad(39.0)$ & 1,425 \\
\hline Rabeprazole 20 mg & 57 & $(0.5)$ & 421 & [360] & 23,970 & 2.72 & 65,198 & $62,082 \quad(10.9)$ & 1,144 \\
\hline Esomeprazole $40 \mathrm{mg}$ & 50 & $(0.5)$ & 427 & [360] & 21,330 & 3.14 & 66,976 & $64,203 \quad(11.3)$ & 1,340 \\
\hline Lansoprazole $15 \mathrm{mg}$ & 13 & $(0.1)$ & 353 & [360] & 4,590 & 3.01 & 13,816 & $13,219 \quad(2.3)$ & 1,063 \\
\hline Esomeprazole $20 \mathrm{mg}$ & 7 & $(0.1)$ & 407 & [450] & 2,850 & 3.19 & 9,092 & $8,721 \quad(1.5)$ & 1,298 \\
\hline Nonformulary subtotal & & & 412.8 & [360] & 419,406 & 2.65 & 624,785 & $570,262(100.0)$ & 1,094 \\
\hline Total & & & & & $3,997,041$ & & $1,089,878$ & & \\
\hline
\end{tabular}

\section{Discussion}

In this study, the prevalence of long-term PPI use was 18\%. This prevalence rate was higher than most published estimates. Previous studies reported a prevalence rate between $0.5 \%$ and $5.0 \% .^{3-10}$ The definition of long-term use varied among the published studies, and some earlier studies included histamine-2 (H2) receptor blockers in the overall estimates. Lassen et al. (2004) considered at least 180 daily doses of antisecretory medication (PPI or H2-blocker) per patient per year as longterm use. ${ }^{3}$ Jacobson et al. (2003) considered patients on more than 90 days of PPI or H2-blocker as "chronic" use. ${ }^{4}$ Goudie et al. (1996) defined long-term antisecretory use as at least 1 repeat (refill) prescription, ${ }^{6}$ and Hungin et al. (1999) defined long-term PPI use as at least 1 repeat prescription in the last 12 months. ${ }^{7}$ Ryder et al. (1994) considered continuous treatment for 6 months or more. ${ }^{8}$ Boutet et al. (1999) considered all repeat prescriptions. ${ }^{9}$ Rubin et al. (1995) considered patients who had received continuous treatment (10-month supply in the previous year) and intermittent therapy (6-10 month supply in the previous year) as long-term use..$^{10}$

Using the same definition of long-term use as in the present study (i.e., at least 120 PPI units in the past year), Reimer and Bytzer (2009) found a prevalence of $2.1 \%$ long-term PPI use, ${ }^{5}$ compared with $18 \%$ in the present study. The reasons for this unusually high prevalence of long-term PPI use in the present study are unknown. One possible explanation was the low threshold for definition of long-term use in the present study (e.g., 120 units could have been dispensed in 1 prescription with twice-daily dosing and a 60-day supply). Second, the veteran population is typically older, obese, male-dominated, and with high prevalence rates of alcohol and tobacco use. ${ }^{13-15}$ These characteristics are often associated with prevalence of GERD. The age and gender distribution seen in this study closely resembles that of the overall VA population in this health system.

As expected, the most common reason for switching from a formulary PPI to nonformulary PPI was persistent symptoms. When adverse reaction was cited as a reason for switching to a nonformulary PPI, it was mostly gastrointestinal in nature. Lansoprazole has a disintegrating formulation that is less likely to clog PEG tubes and is recommended in patients with PEG tubes. Less than $1 \%$ of patients on nonformulary PPI had a PEG tube. Forty percent of those who switched to a nonformulary PPI as a result of persistent symptoms were on a once-daily dosing regimen, and the dosing regimen of $18 \%$ of the patients was unknown. This pattern is not consistent with the American Gastroenterological Association (AGA; 2008) definition of treatment failure, in which only patients whose symptoms have not adequately responded to twice-daily PPI therapy (daily dose is not mentioned) should be considered treatment failures. ${ }^{16}$

The VA health care system requires a pharmacy consult to permit use of a nonformulary PPI, but there is no clear guideline for what constitutes therapeutic failure or intolerance to the nonformulary PPI. In this setting, only $9.7 \%$ of all long-term PPI users received nonformulary PPI. However, the majority of PPI cost was still attributable to nonformulary PPI use because the mean cost per patient was higher for nonformulary PPI. The VA contract prices for nonformulary PPIs would have to be significantly lower for the total expenditure to be lower. VA contract prices for PPIs reflect differences between brand and generic drugs. Before the entire class of PPIs become available in generic form and, therefore, are less expensive, we suggest that there is an opportunity to reduce nonformulary PPI use and avoid excess drug cost. 


\section{Methods to Reduce Nonformulary PPI Use}

Before a nonformulary PPI consult is placed, prescribers should verify optimal use of the formulary PPI. Even though labels on PPI bottles instruct patients to take the medication 30 minutes before a meal, studies suggest that among patients with persistent GERD symptoms, up to 54\% of patients use PPIs suboptimally. ${ }^{17}$ Patients who report persistent symptoms on a oncedaily PPI regimen should have their dosing increased to twicedaily before a nonformulary consult is placed. A review by Liu and Saltzman (2009) suggested that up to 25\% of patients with refractory symptoms on once-daily PPI treatment would respond to an increase to twice-daily PPI dosing. ${ }^{18}$ A position statement from the AGA also recommends twice-daily dosing in patients with persistent symptoms on once-daily dosing. ${ }^{16}$

When adverse reaction is cited as a reason for nonformulary PPI consult, a careful review of the symptoms and all medications the patient is taking should be done. Some of the adverse reactions attributable to PPI use in this study may not have been due to PPI use. The reason for PPI use should be included in the pharmacy consult. Finally, prescribers should be made aware of cost differences between the various PPIs, particularly because no PPI has been shown to be superior to other PPIs.

\section{Limitations}

First, the present study was conducted in 1 VA health care system in the Pacific region composed of 1 medical center and 5 community clinics. Our findings may not be generalizable to commercial health plans. Second, the study may not have captured all PPI use because PPI prescriptions could have been filled outside the VA system, and the VA does not cover overthe-counter (OTC) drugs, such as omeprazole OTC. Third, because we did not assess both units dispensed and days supply, it is possible that patients were included in the present study who received as little as 1 prescription of PPI with twicedaily dosing (e.g., 120 units dispensed as a 60-day supply). Fourth, the study did not look at differences in symptom control, health-related quality of life, or lost productivity between long-term formulary and nonformulary PPI users. These factors may contribute to indirect cost.

\section{Conclusions}

The study revealed an unusually high prevalence of long-term PPI use among veterans. Most veterans used the formulary PPI. However, based on actual incurred pharmacy costs, nonformulary PPI users accounted for greater PPI cost. Opportunities to reduce nonformulary PPI use in order to reduce overall expenditures on PPIs include verification of optimal PPI use, titration to twice-daily dosing, and confirmation of adverse reaction attributable to PPI.

\section{Authors}

ADEWALE B. AJUMOBI, MD, MBA, FACP, is Assistant Professor, Loma Linda University, Loma Linda, California, and Attending Physician in internal medicine, Loma Linda VA Healthcare System, Loma Linda, California. RONALD VUONG, BS, is a second-year medical student, Loma Linda University, Loma Linda, California. HYCIENTH AHANEKU, MBBS, MPH, is a PhD student, Department of Epidemiology, University of Texas, Houston, Texas.

AUTHOR CORRESPONDENCE: Adewale B. Ajumobi, MD, 11201 Benton St., Loma Linda, CA 92357. Tel.: 909.825.7085; E-mail: adewaleajums@yahoo.com.

\section{DISCLOSURES}

There was no external funding for this manuscript, and the authors report no financial or other potential conflicts of interest related to the subject of this article. Ajumobi conceived and designed the study and collected the data, with the assistance of Vuong. Ajumobi interpreted the data and wrote and revised the manuscript, with the assistance of Vuong and Ahaneku.

\section{ACKNOWLEDGEMENTS}

The authors acknowledge the help of Phillip Ng, PharmD, a clinical informatics pharmacist in providing a master list of all patients prescribed a PPI in the study period, and Mike Choi, MPH, a program analyst in providing guidance with demographic data.

\section{REFERENCES}

1. IMS Health. Top therapeutic classes by U.S. sales, 2009. Updated April 6, 2010. Available at: http://imshealth.com/deployedfiles/imshealth/Global/ Content/StaticFile/Top_Line_Data/Top\%20Therapy\%20Classes\%20by\%20 U.S.Sales.pdf. Accessed December 18, 2011.

2. Raghunath AS, O'Morain C, McLoughlin RC. Review article: the longterm use of proton pump inhibitors. Aliment Pharmacol Ther. 2005;22(Suppl 1):S55-S63.

3. Lassen A, Hallas J, Schaffalitzky De Muckadell OB. Use of anti-secretory medication: a population-based cohort study. Aliment Pharmacol Ther. 2004;20(5):577-83. Available at: http://onlinelibrary.wiley.com/doi/10.1111/ j.1365-2036.2004.02120.x/pdf. Accessed December 18, 2011.

4. Jacobson BC, Ferris TG, Shea TL, Mahlis EM, Lee TH, Wang TC. Who is using chronic acid suppression therapy and why? Am J Gastroenterol. 2003;98(1):51-58

5. Reimer C, Bytzer P. Clinical trial: long-term use of proton pump inhibitors in primary care patients-a cross-sectional analysis of 901 patients. Aliment Pharmacol Ther. 2009;30(7):725-32.

6. Goudie BM, McKenzie PE, Cipriano J, Griffin EM, Murray FE. Repeat prescribing of ulcer healing drugs in general practice-prevalence and underlying diagnosis. Aliment Pharmacol Ther. 1996;10(2):147-50.

7. Hungin AP, Rubin GP, O'Flanagan H. Long-term prescribing of proton pump inhibitors in general practice. Br J Gen Pract. 1999;49(443):45153. Available at: http://www.ncbi.nlm.nih.gov/pmc/articles/ PMC1313442/?tool=pubmed. Accessed December 18, 2011.

8. Ryder SD, O'Reilly S, Miller RJ, Ross J, Jacyna MR, Levi AJ. Long-term acid suppressing treatment in general practice. BMJ. 1994;308(6932):827-30. Available at: http://www.ncbi.nlm.nih.gov/pmc/articles/PMC2539987/pdf/ bmj00433-0033.pdf. Accessed December 18, 2011. 
9. Boutet R, Wilcock M, MacKenzie I. Survey on repeat prescribing for acid suppression drugs in primary care in Cornwall and the Isles of Scilly. Aliment Pharmacol Ther. 1999;13(6):813-17. Available at: http://onlinelibrary. wiley.com/doi/10.1046/j.1365-2036.1999.00524.x/pdf. Accessed December $18,2011$.

10. Rubin GP, Contractor B, Bramble MG. The use of long-term acid suppression therapy. Br J Clin Pract. 1995;49(3):119-20.

11. Talley NJ, Lauritsen K, Tunturi-Hihnala H, et al. Esomeprazole $20 \mathrm{mg}$ maintains symptom control in endoscopy-negative gastro-oesophageal reflux disease: a controlled trial of 'on-demand' therapy for 6 months. Aliment Pharmacol Ther. 2001;15(3):347-54. Available at: http://onlinelibrary. wiley.com/doi/10.1046/j.1365-2036.2001.00943.x/pdf. Accessed December $18,2011$.

12. Bytzer P, Blum A, De Herdt D, DuBois D; Trial investigators. Six-month trial of on-demand rabeprazole $10 \mathrm{mg}$ maintains symptom relief in patients with non-erosive reflux disease. Aliment Pharmacol Ther. 2004;20(2):18188. Available at: http://onlinelibrary.wiley.com/doi/10.1111/j.1365-

2036.2004.01999.x/pdf. Accessed December 18, 2011.
13. Nelson KM. The burden of obesity among a national probability sample of veterans. J Gen Intern Med. 2006;21(9):915-19. Available at: http://www. ncbi.nlm.nih.gov/pmc/articles/PMC1831589/?tool=pubmed. Accessed December 18, 2011.

14. Thompson WH, St-Hilaire S. Prevalence of chronic pulmonary disease and tobacco use in veterans at Boise Veterans Affairs Medical Center. Respir Care. 2010;55(5):555-60.

15. Milliken CS, Auchterlonie JL, Hoge CW. Longitudinal assessment of mental health problems among active and reserve component soldiers returning from the Iraq war. JAMA. 2007;298(18):2141-48.

16. Kahrilas PJ, Shaheen NJ, Vaezi MF, et al.; American Gastroenterological Association. American Gastroenterological Association Medical Position Statement on the management of gastroesophageal reflux disease. Gastroenterology. 2008;135(4):1383-91.

17. Gunaratnam NT, Jessup TP, Inadomi J, Lascewski DP. Sub-optimal proton pump inhibitor dosing is prevalent in patients with poorly controlled gastro-oesophageal reflux disease. Aliment Pharmacol Ther. 2006;23(10):1473-77. Available at: http://onlinelibrary.wiley.com/ doi/10.1111/j.1365-2036.2006.02911.x/pdf. Accessed December 18, 2011.

18. Liu JJ, Saltzman JR. Refractory gastro-oesophageal reflux disease: diagnosis and management. Drugs. 2009;69(14):1935-44. 